ARTICLE

\title{
Cell culture NAIL-MS allows insight into human tRNA and rRNA modification dynamics in vivo
}

\author{
Matthias Heiss ${ }^{1}$, Felix Hagelskamp ${ }^{1}$, Virginie Marchand (1) ${ }^{2}$, Yuri Motorin ${ }^{2}$ \& Stefanie Kellner (i) 1,3凶
}

Recently, studies about RNA modification dynamics in human RNAs are among the most controversially discussed. As a main reason, we identified the unavailability of a technique which allows the investigation of the temporal processing of RNA transcripts. Here, we present nucleic acid isotope labeling coupled mass spectrometry (NAIL-MS) for efficient, monoisotopic stable isotope labeling in both RNA and DNA in standard cell culture. We design pulse chase experiments and study the temporal placement of modified nucleosides in tRNA ${ }^{\text {Phe }}$ and $18 \mathrm{~S}$ rRNA. In existing RNAs, we observe a time-dependent constant loss of modified nucleosides which is masked by post-transcriptional methylation mechanisms and thus undetectable without NAIL-MS. During alkylation stress, NAIL-MS reveals an adaptation of tRNA modifications in new transcripts but not existing ones. Overall, we present a fast and reliable stable isotope labeling strategy which allows in-depth study of RNA modification dynamics in human cell culture.

\footnotetext{
${ }^{1}$ Department of Chemistry, Ludwig-Maximilians-University Munich, Butenandtstr. 5-13, 81377 Munich, Germany. ${ }^{2}$ Université de Lorraine, CNRS, Inserm, UMS2008/US40 IBSLor and UMR7365 IMoPA, F-54000 Nancy, France. ${ }^{3}$ Institute of Pharmaceutical Chemistry, Goethe-University Frankfurt, Max-vonLaue-Str, 9, 60438 Frankfurt, Germany. ${ }^{凶}$ email: stefanie.kellner@cup.uni-muenchen.de
} 
M ost RNAs studied to date were found to be covalently modified by dedicated enzymes in a site-specific manner. In addition to the placement of RNA modifications by RNA writer enzymes, their direct removal through e.g., demethylation by RNA erasers was reported. In human cells, the a-ketoglutarate dependent dioxygenases ALKBH5 and/or FTO were found to catalyze the demethylation of e.g., (2'-O-methyl-) N6-methyladenosine $\left(\mathrm{m}^{6} \mathrm{~A}(\mathrm{~m})\right)$ in $\mathrm{mRNA}^{1,2}$ and thus influence, e.g., the stability and translational function of $\mathrm{mRNA}^{1,3-8}$.

For human tRNAs, a similar relationship of RNA writers and erasers was observed. E.g., ALKBH1 demethylates 1-methyladenosine $\left(\mathrm{m}^{1} \mathrm{~A}\right)$ and appears to be responsive to glucose starvation in some cell lines ${ }^{9}$. Considering the half-life of mammalian tRNAs $\left(\sim 100 \mathrm{~h}^{10}\right)$, a fast adaptation by removal of modified residues appears beneficial to react to changes in the cellular environment ${ }^{11}$. Unfortunately, it is currently not possible to analyze the speed of both modification and demethylation reactions inside human cells. Thus, it is not possible to study the impact of external stimuli and stress on human RNA modification kinetics and processing of mature RNA.

tRNA is the most extensive and chemically diverse modified RNA with $\sim 10-15 \%$ of all nucleosides being modified ${ }^{12}$. Recent studies showed that certain modified nucleosides in specific tRNAs are only partially modified ${ }^{13,14}$ and that tRNA modification abundance differs among tissues ${ }^{15,16}$. This would allow for an adaptation of translation by tRNA modification as recently suggested ${ }^{17}$. While the speed of tRNA amino acid charging ${ }^{18}$ and tRNA transcription and half-live are known ${ }^{10}$, the speed of modification processes is difficult to study. For example, tRNA ${ }^{\text {Phe }}$ is heavily post-transcriptionally modified and in addition one of the best studied RNAs ${ }^{19-21}$. By using stable isotope labeled tRNA ${ }^{\text {Phe }}$ substrate and cellular extracts, the modification dynamics and hierarchy was recently solved in S. cerevisiae using NMR spectroscopy ${ }^{22}$. Under the influence of chemical stress, $S$. cerevisiae was reported to adapt its abundance of tRNA modifications and thus influence its translation and the term stress induced tRNA reprogramming was coined ${ }^{11,23}$. Similar evidence has been observed in other organisms, including mammals ${ }^{24}$. In this context, the question remains by which mechanism and how fast tRNA modifications respond to external stimuli.

In contrast to tRNA, $18 \mathrm{~S}$ rRNA is mainly modified by methylation of ribose and altogether only 2.05\% nucleosides are modified. While tRNA modifications are easily accessible for potential RNA erasers, rRNA modifications are placed in the functional regions of the ribosome ${ }^{25}$. Although modified sites in rRNA have been reported to regulate translation initiation by promoting the recognition of different mRNA subsets ${ }^{26}$, their inaccessibility in mature ribosomes makes them a difficult target for RNA erasers.

Current studies of RNA modifications are limited to either mass spectrometric analysis ${ }^{16}$ or sequencing ${ }^{27,28}$. Both techniques provide information on the modification status at the time point of sample harvest and give no details on the mechanisms of RNA modification adaptation. To overcome this limitation, we have recently developed NAIL-MS (nucleic acid isotope labeling coupled mass spectrometry) in bacteria ${ }^{29,30}$ and yeast $^{31}$, which reveals the dynamics of RNA modification processes. The technique is based on metabolic stable isotope labeling of RNA using simple nutrients with e.g., carbon-13, nitrogen-15, or sulfur-34. By combining differentially labeled media in a pulse chase set-up, we recently succeeded to observe tRNA demethylation through AlkB in E. coli in vivo. Currently, NAIL-MS studies are not available for human cell lines as a monoisotopic labeling of all four canonical nucleosides is highly complex.

Here, we report a fast and reliable method for monoisotopic stable isotope labeling in both RNA and DNA (>95\% within
7 days) in common human cell lines and growth media. We apply the cell culture NAIL-MS method and reveal the dynamics of human tRNA and 18S rRNA modifications in depths unreachable by any other tool for RNA modification analysis. Furthermore, we resolve the mechanism of stress induced tRNA modification reprogramming in the presence of methylation stress. With cell culture NAIL-MS it is finally possible to study the speed of both modification and demethylation reactions inside human cells. Thus, it will be possible to study the impact of external stimuli and stress on human RNA modification kinetics and processing of mature RNA.

\section{Results}

Absolute quantification of human tRNA ${ }^{\text {Phe }}$ modifications. tRNA $^{\text {Phe }}$ is heavily post-transcriptionally modified and in addition one of the best studied RNAs ${ }^{19-22}$. Thus, it is an ideal model to study the temporal dynamics of its modifications. In a first step, we purified tRNA $^{\text {Phe }}{ }_{\text {GAA }}$ from HEK 293 cells using a complementary DNA probe ${ }^{13}$. We used our established isotope dilution LC-MS/MS analysis for absolute quantification of modified nucleosides and plotted the modification profile in Fig. ${ }^{16}$. For pseudouridine $(\Psi)$, dihydrouridine $(\mathrm{D}), 2,2$-dimethylguanosine $\left(\mathrm{m}^{2}{ }_{2} \mathrm{G}\right)$, and $2^{\prime}-\mathrm{O}$-methylguanosine $(\mathrm{Gm})$ our experimental data matches the expected values and we see full modification ${ }^{32}$. The abundance of 1-methyladenosine $\left(\mathrm{m}^{1} \mathrm{~A}\right.$ position 14 and 58$)$, 7-methylguanosine $\left(\mathrm{m}^{7} \mathrm{G}\right), 5$-methyluridine $\left(\mathrm{m}^{5} \mathrm{U}\right.$ or $\left.\mathrm{rT}\right)$, and $2^{\prime}$ O-methylcytidine $(\mathrm{Cm})$ is lower compared to the literature, presumably due to partial modification of the respective sites. Partial modification has been suggested to play a role in stress induced reprogramming of tRNA modifications ${ }^{17}$. The abundance of 5-methylcytidine $\left(\mathrm{m}^{5} \mathrm{C}\right)$ is slightly higher than expected and can be explained by the additional methylation of $\mathrm{C} 48$ by NSUN $2^{33}$

Although 1-methylguanosine $\left(\mathrm{m}^{1} \mathrm{G}\right)$ is not reported in tRNA $^{\text {Phe }}{ }_{\text {GAA }}$, we found around $0.3 \mathrm{~m}^{1} \mathrm{G}$ per tRNA. This observation can be explained by the fact that $\mathrm{m}^{1} \mathrm{G}$ is a precursor during the biosynthesis of wybutosine (yW), a hypermodified nucleoside reported at position 37 of tRNA ${ }^{\mathrm{Phe}}{ }_{\mathrm{GAA}}{ }^{34,35}$. Due to the unavailability of a synthetic standard, $\mathrm{yW}$ could not be quantified in this study. In addition, we also quantified the abundance of other modified nucleosides (Table S1). We found around 0.36 methyladenosine $\left(\mathrm{m}^{6} \mathrm{~A}\right)$ per tRNA, potentially caused by intracellular Dimroth rearrangement of $\mathrm{m}^{1} \mathrm{~A}^{36}$. In addition, we found 0.063 inosine (I) and 0.026 1-methylinosine $\left(\mathrm{m}^{1} \mathrm{I}\right)$ per tRNA $^{\text {Phe }}$. These are most likely artefacts from spontaneous A and $\mathrm{m}^{1} \mathrm{~A}$ deamination. All other modified nucleosides were found with an abundance of less than $1.6 \%$ (e.g., $0.016 \mathrm{~N}^{6}$-threonylcarbamoyladenosine $\left(t^{6} \mathrm{~A}\right)$ per tRNA) which indicates a high purity of isolated tRNA ${ }^{\text {Phe }}$. Northern Blot analysis and deep sequencing of purified tRNA ${ }_{\text {Phe }}$ GAA sample indicated that this tRNA represents $>90 \%$ with only minor contaminations by other tRNAs and rRNA (Figs. S1a and S2).

Overall, the detected quantities of modified nucleosides from purified tRNA ${ }^{\text {Phe }}{ }_{\text {GAA }}$ are in accordance with the reported values and thus it is a suitable model to study the temporal placement of modified nucleosides.

Stable isotope labeling of RNA in human cell culture. For this purpose, a method is needed which allows the discrimination of mature RNA from new transcripts. NAIL-MS (nucleic acid isotope labeling coupled mass spectrometry) relies on the metabolic incorporation of stable isotope labeled nutrients into RNA and allows the distinction of original RNA and new RNA within a pulse chase experiment. With this tool, we studied the temporal placement of modified nucleosides in S. cerevisiae total tRNA ${ }^{31}$ 

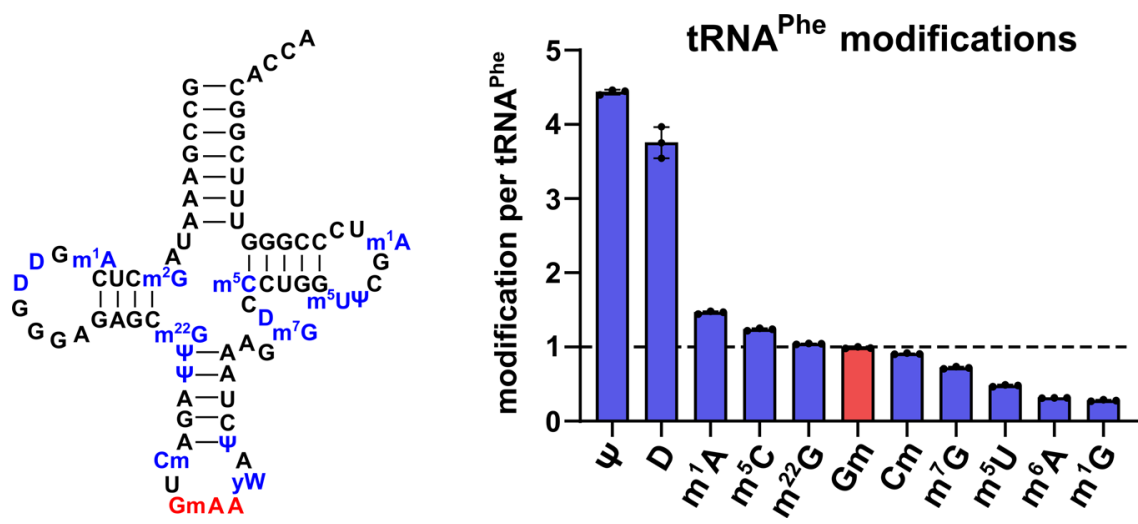

Fig. 1 Absolute quantification of human tRNA ${ }^{\text {Phe }}{ }_{\text {GAA }}$ modifications. The tRNA cloverleaf on the left shows the expected sequence of human tRNA Phe ${ }_{\text {GAA }}$ including reported modifications ${ }^{32}$. Right: Absolute quantification of purified tRNA ${ }^{\text {Phe }}{ }_{\text {GAA }}$ from HEK 293 cells done by LC-MS/MS. All experiments are from $n=3$ biol. replicates. Bars reflect the mean and error bars reflect standard deviation.

and the demethylation during tRNA repair in E. coli ${ }^{37}$. Both organisms are rather simple and can be grown in minimal media with controlled availability of stable isotope labeled nutrients.

In contrast, human cell culture medium is highly complex and requires the addition of fetal bovine serum (FBS). FBS is a natural product of undefined composition and variable concentration of metabolites. Thus, a complete and monoisotopic labeling of nucleosides and even nucleobases for a pulse chase NAIL-MS assay is challenging.

From our experience, the target isotopologue of a nucleoside must be at least $3 \mathrm{u}$ heavier compared to the naturally occurring nucleoside to avoid false positive results by the detection of the natural carbon-13 signals.

De novo synthesis of nucleosides utilizes several amino acids such as glutamine or aspartic acid (Fig. S3A, B) ${ }^{38}$. Hence, we supplemented the growth media with stable isotope labeled glutamine. After 5 days (2 passages), we observed the expected stable isotope labeling of RNA (Fig. S3C). Cytidine, guanosine and adenosine got a mass increase of +2 whereas uridine just increased by +1 . Due to the overlap with naturally occurring $\left({ }^{13} \mathrm{C}\right)$-isotopologues, this mass increase was not sufficient for our planned experiments.

As recently described, it is possible to use glucose-free growth medium and supplement with ${ }^{13} \mathrm{C}_{6}$-glucose ${ }^{37}$. The feeding with ${ }^{13} \mathrm{C}_{6}$-glucose leads to the formation of nucleosides with a variable number of ${ }^{13} \mathrm{C}$-atoms per nucleoside (Fig. S3C). During method development, we utilized the non-monoisotopic nature of ${ }^{13} \mathrm{C}_{6}$ glucose labeling to test the incorporation efficiency of various unlabeled metabolites. Addition of aspartate and pyruvate did not allow the envisioned monoisotopic labeling (Fig. S4). The addition of the nucleobases adenine and uracil resulted in ribose labeled purines but undefined labeled pyrimidines. This indicates a direct usage of adenine from the medium which is then enzymatically connected with ${ }^{13} \mathrm{C}_{5}$-ribose followed by further processing to guanosine and the respective triphosphates (Fig. S3B). RNA supplemented with the nucleosides adenosine and uridine showed undefined labeled purines and only unlabeled pyrimidines (Fig. S5). This indicates that uridine is taken up by the cells and immediately utilized for cytidine and RNA synthesis (Fig. S3A). In summary, our data indicates that the addition of adenine and uridine blocks de novo purine and pyrimidine synthesis (Fig. S3A, B) and ${ }^{13} \mathrm{C}_{6}$-glucose medium is not necessary for our labeling strategy (Fig. S5). Concentration optimization of both compounds revealed that final concentrations of $0.1 \mathrm{mM}$ adenine and $0.2 \mathrm{mM}$ uridine in the ${ }^{13} \mathrm{C}_{6}$-glucose medium are needed to suppress signals from de novo synthesized nucleosides (Fig. S6).
Hence, we used ${ }^{15} \mathrm{~N}_{5}$-adenine and ${ }^{13} \mathrm{C}_{5},{ }^{15} \mathrm{~N}_{2}$-uridine (Fig. 2a) in medium with unlabeled glucose. The high-resolution mass spectra of the resulting RNA nucleosides showed the desired labeling for $>95 \%$ of all canonical nucleosides after 7 days (Fig. 2b). A +7 mass increase is observed for cytidine and uridine and $a+5$ and +4 mass increase for adenosine and guanosine, respectively. By using dialyzed FBS, the signal of unlabeled adenosine could be further reduced in comparison to normal FBS (Fig. S7). Similarly, DNA nucleosides become stable isotope labeled (Fig. S8).

With these metabolites, a pulse chase NAIL-MS study is possible in human cell culture. To this end, we achieve excellent labeling in HEK 293, HAP and HeLa cell lines using supplemented DMEM, RPMI or IMDM medium (Fig. S9).

In mouse embryonic stem cells (mESC), the addition of ${ }^{15} \mathrm{~N}_{5^{-}}$ adenine and ${ }^{13} \mathrm{C}_{5},{ }^{15} \mathrm{~N}_{2}$-uridine leads to non-monoisotopic labeling. Here, the labeling efficiency is improved from 35 to $70 \%$ by the usage of dialyzed FBS (Fig. S10).

In HEK 293 cells, the signals of new tRNA transcripts became detectable and quantifiable after $120 \mathrm{~min}$ of labeling (Figs. S11/ S12).

Most modified nucleosides in RNA carry one or more methylations. To follow the fate of these methylated nucleosides in the context of RNA maturation and methylation damage response, we used $\mathrm{CD}_{3}$-labeled methionine. Methionine is the precursor amino acid of S-adenosylmethionine (SAM) which in turn is cofactor of most RNA methyltransferases. In the presence of $\mathrm{CD}_{3}$-methionine, most methylated nucleosides get a mass increase of +3 and can thus be distinguished from nucleosides modified in the presence of unlabeled methionine. High resolution mass spectra of fully labeled $\mathrm{m}^{5} \mathrm{C}, \mathrm{m}^{7} \mathrm{G}$, and $\mathrm{m}^{1} \mathrm{~A}$ are exemplarily shown in Fig. 2c. In order to achieve complete labeling of methyl-groups, methionine depleted medium has to be used. We chose DMEM D0422 (from Sigma-Aldrich, Munich, Germany) which lacks glutamine, cystine and methionine (Fig. S13). Neither cell shape nor growth speed were influenced by the labeling and both were comparable to standard DMEM (e.g., D6546, from Sigma-Aldrich) (Fig. S14).

The combination of nucleoside and methyl-group labeling allows the design of elegant pulse chase studies to follow the fate of RNA in human cells.

Validation of human cell culture NAIL-MS. After finding a suitable way for monoisotopic labeling of RNA in human cells, we wanted to rule out the possibility of the labeling itself impacting the abundance of RNA modifications. For this purpose, cells were grown in labeled or unlabeled media for 7 days. Both media 
a

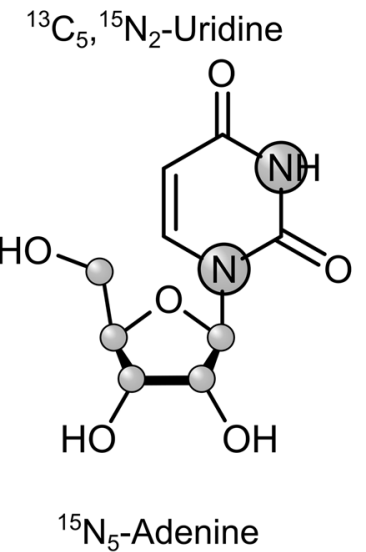<smiles></smiles>

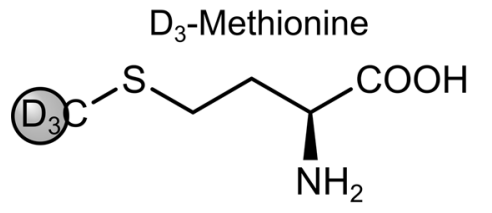

b
Adenosine RT: $7.72-7.84$

RT: 3.61 - 3.82 RT: $4.71-4.87$

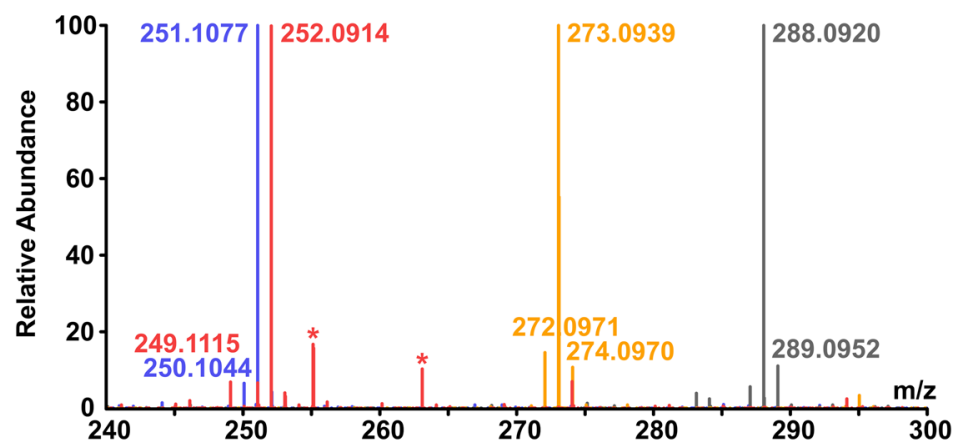

C

$$
\begin{aligned}
& \mathrm{m}^{5} \mathrm{C}\left(\text { or } \mathrm{m}^{3} \mathrm{C}\right) \\
& \text { RT: } 5.42
\end{aligned}
$$

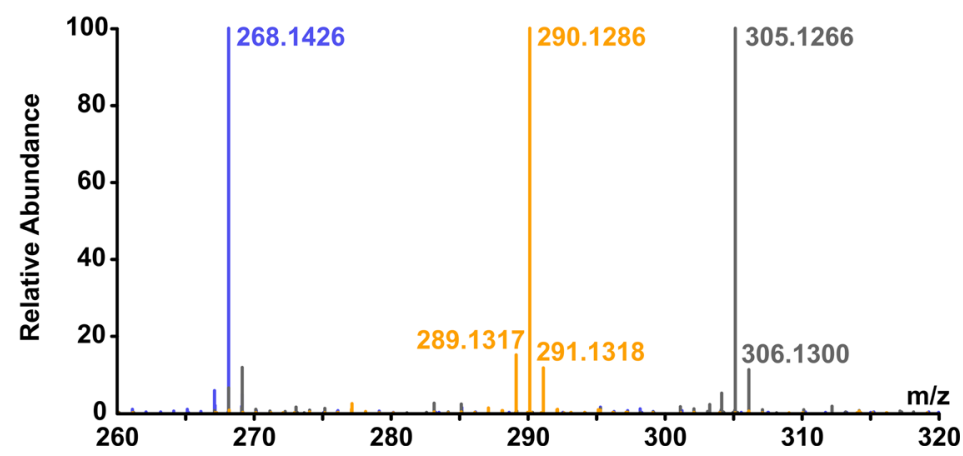

Fig. 2 High resolution mass spectra of stable isotope labeled nucleosides from cell culture. a Labeling of compounds used for stable isotope labeling in cell culture. Grey circles indicate the positions of isotopes $\left({ }^{13} \mathrm{C},{ }^{15} \mathrm{~N}\right.$, or $\left.{ }^{2} \mathrm{H} / \mathrm{D}\right)$. b Merged high resolution mass spectra of the 4 canonical nucleosides of total tRNA after labeling of HEK 293 cells with shown compounds for 7 days. Background signals are marked with asterisks. c Merged high resolution mass spectra of three exemplary modifications $\left(\mathrm{m}^{5} \mathrm{C}, \mathrm{m}^{7} \mathrm{G}\right.$, and $\left.\mathrm{m}^{1} \mathrm{~A}\right)$ in total tRNA after stable isotope labeling of HEK 293 cells for 7 days.

contained adenine, uridine and methionine as either unlabeled or labeled nutrients. Cells were harvested with TRI reagent and split into two aliquots. One aliquot $(2 / 3 \mathrm{Vol})$ was used for immediate RNA isolation and purification, while the remaining aliquot of the labeled and unlabeled cells were mixed and RNA was coisolated and co-purified (Figs. 3a and S15). The total tRNA was enzymatically digested to nucleosides and their abundance determined by isotope dilution mass spectrometry ${ }^{16}$. In the aliquot from unlabeled samples, only unlabeled nucleosides were detectable, while the aliquot of the labeled cells showed mainly signals $(>98 \%)$ for labeled nucleosides. As expected from the mixed sample, we detected unlabeled and labeled isotopologues of all canonicals in similar amounts (Fig. 3b). Next, we quantified the abundance of modified nucleosides. For normalization, unlabeled modifications were referenced to unlabeled canonicals and labeled modifications were referenced to labeled canonicals. The calculated quantities of modified nucleosides present in tRNA ${ }^{\text {Phe }}$ (according to Fig. 1) are plotted for the unlabeled against labeled tRNA in Fig. 3c. This validation revealed that the quantities of modified nucleosides are independent of the media and that the labeling procedure itself does not interfere with the isotope dilution MS quantification. This finding is in accordance with our northern blot data, where we observe no change in tRNA $^{\text {Phe }}$ abundance in dependence of the labeling medium (Fig. S1b). The deviation from the expected values (dotted diagonal line) is the error of this NAIL-MS experiment and the limitation to detect differences in a biological setup (also see Fig. S16). E.g., In total tRNA, 2'-O-methyluridine (Um) has the largest error as its abundance deviates 1.6 fold in labeled and unlabeled media.

The promising results from the validation experiments allowed the design of pulse chase experiments. Such experiments start with cells seeded in medium-I which, upon experiment initiation, is exchanged to medium-II with different isotopically labeled nutrients. The concept is shown in Fig. 3d. To rule out possible differences in the results in dependence of the starting medium, we designed a brief validation experiment. In the forward experiment, cells are seeded in unlabeled medium and switched to labeled medium while the reverse experiment starts in labeled medium (after a 7 day labeling period) before switching to unlabeled.

For analysis of modified nucleoside quantities, we harvested the cells and extracted total tRNA after switching to medium-II (time points $0,6,24$, and $48 \mathrm{~h}$ ). To assess the suitability of the method for temporal placement of modified nucleosides into the total tRNA, we focused on the abundance of new modified nucleosides in the newly transcribed tRNA. For direct comparison, the ratio of found $(6,24,48 \mathrm{~h}$-new transcripts) and expected ( $0 \mathrm{~h}$-original transcripts) modified nucleoside quantity was formed and plotted over time. As expected, we observed the incorporation of modified nucleosides into the new tRNA after medium exchange. While the timing of the tRNA modification process was comparable in the reverse and forward experiment, the start values were obscured in the reverse experiment due to low, but detectable signals of unlabeled nucleosides. For this and economic considerations, we decided to perform forward pulse chase 
a

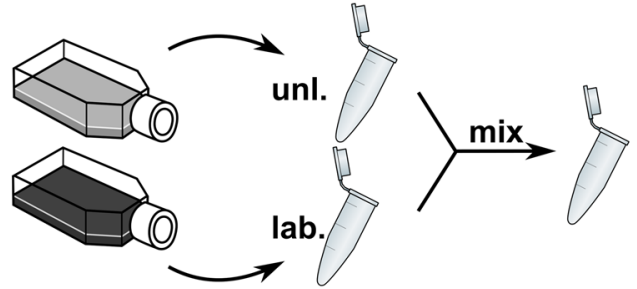

b

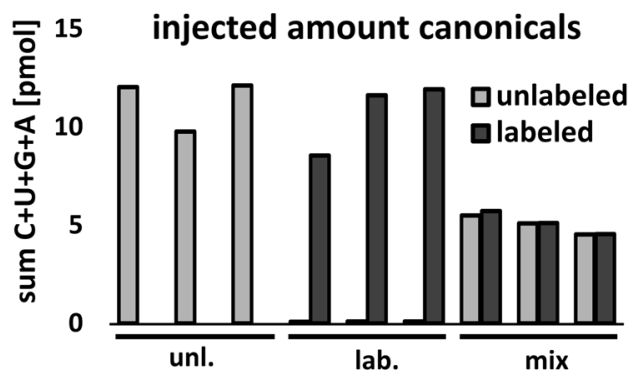

C

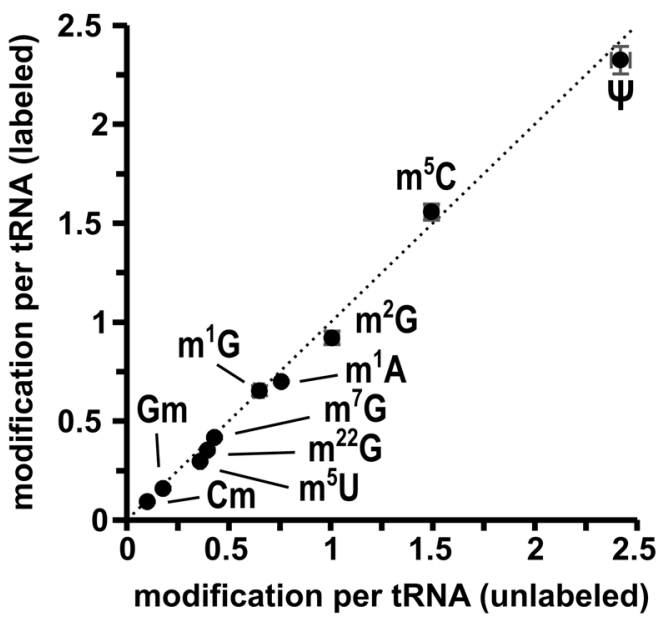

d

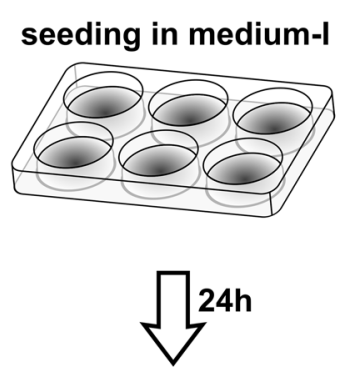

$\sim 30 \%$ confluency switch to medium-II
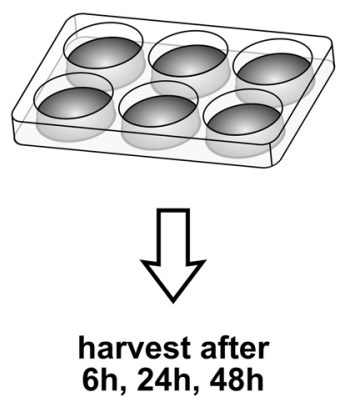

e

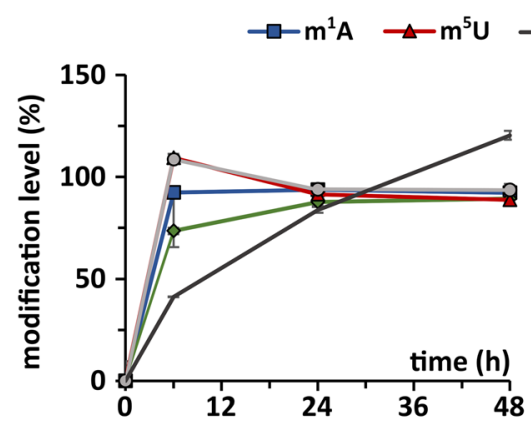

forward

reverse

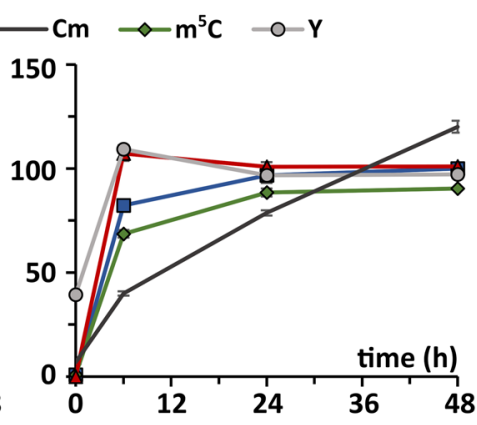

$\neg-m^{1} G \quad \triangle-m^{7} G-G m \leadsto-m^{2} G \quad \circ-m^{22} G$
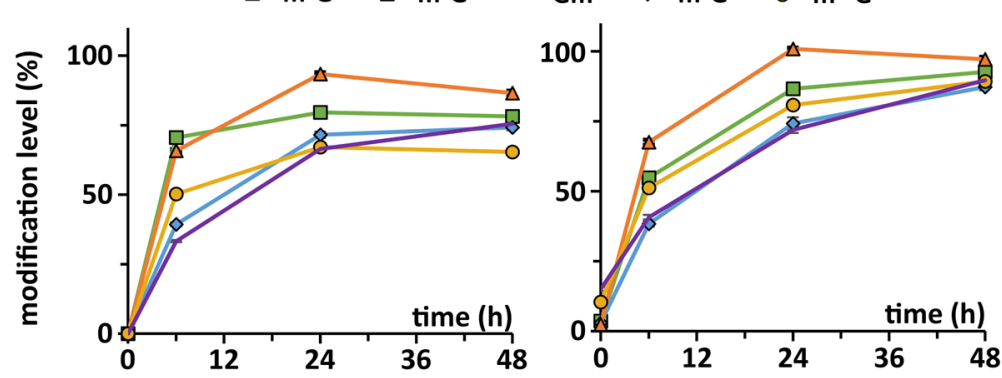

Fig. 3 Validation of cell culture NAIL-MS. a Cells were grown in unlabeled or fully labeled media for 7 days. Upon harvesting one aliquot was mixed prior to processing (mix). Total tRNA was purified and all samples were analyzed by LC-MS/MS. b Summed amount of canonical nucleosides (C $+\mathrm{U}+\mathrm{G}+\mathrm{A}$ ) detected by LC-MS/MS for unlabeled and labeled isotopologues. The bars show single replicates of three unlabeled, three labeled and three mixed aliquots. c Abundance of labeled modifications plotted against the abundance of unlabeled modifications in the mix samples. The dotted line indicates the location of the expected values as a visual guide. $\mathbf{d}$ Experimental setup of time course study to investigate temporal placement of RNA modifications. The experiment was done forward (start with unlabeled, change to labeled medium) and reverse (vice versa). e Results of time course study. Plotted on the $y$ axis is the abundance of modification in new transcripts normalized to the abundance before experiment initiation $(T=0)$. Note: In the reverse experiment, minor signals of unlabeled nucleosides are present at $T=0$ and thus the starting value is sometimes larger than $0 \%$. All experiments were done with purified total tRNA and are from $n=3$ biol. replicates. Symbols reflect the mean and error bars reflect standard deviation.

experiments in the future to avoid the excessive use of labeled medium.

Temporal placement of modified nucleosides in RNA. From a biological perspective, we observed that most modified nucleosides reach their final abundance (100\% compared to the starting point) within $48 \mathrm{~h}$ (Fig. 3e). Some modified nucleosides, such as $\mathrm{m}^{1} \mathrm{~A}, \mathrm{~m}^{5} \mathrm{C}, \Psi$, and $\mathrm{m}^{5} \mathrm{U}$, are already $>90 \%$ after $6 \mathrm{~h}$ which indicates a fast incorporation after transcription. These modified nucleosides are located in the structure-stabilizing positions of the tRNA's D-loops and TYC-loops and thus a fast and reliable modification is to be expected ${ }^{39} . \mathrm{m}^{7} \mathrm{G}$ is also involved in structure stabilization ${ }^{40}$ and yet, this methylation is placed rather slowly in total tRNA. Other modified nucleosides such as $\mathrm{Cm}, \mathrm{Gm}$, and the base-methylated $G$ derivatives $\left(\mathrm{m}^{1} \mathrm{G}, \mathrm{m}^{2} \mathrm{G}\right.$, and $\left.\mathrm{m}^{22} \mathrm{G}\right)$ are incorporated more slowly and the final modification density is not reached within $48 \mathrm{~h}$. 

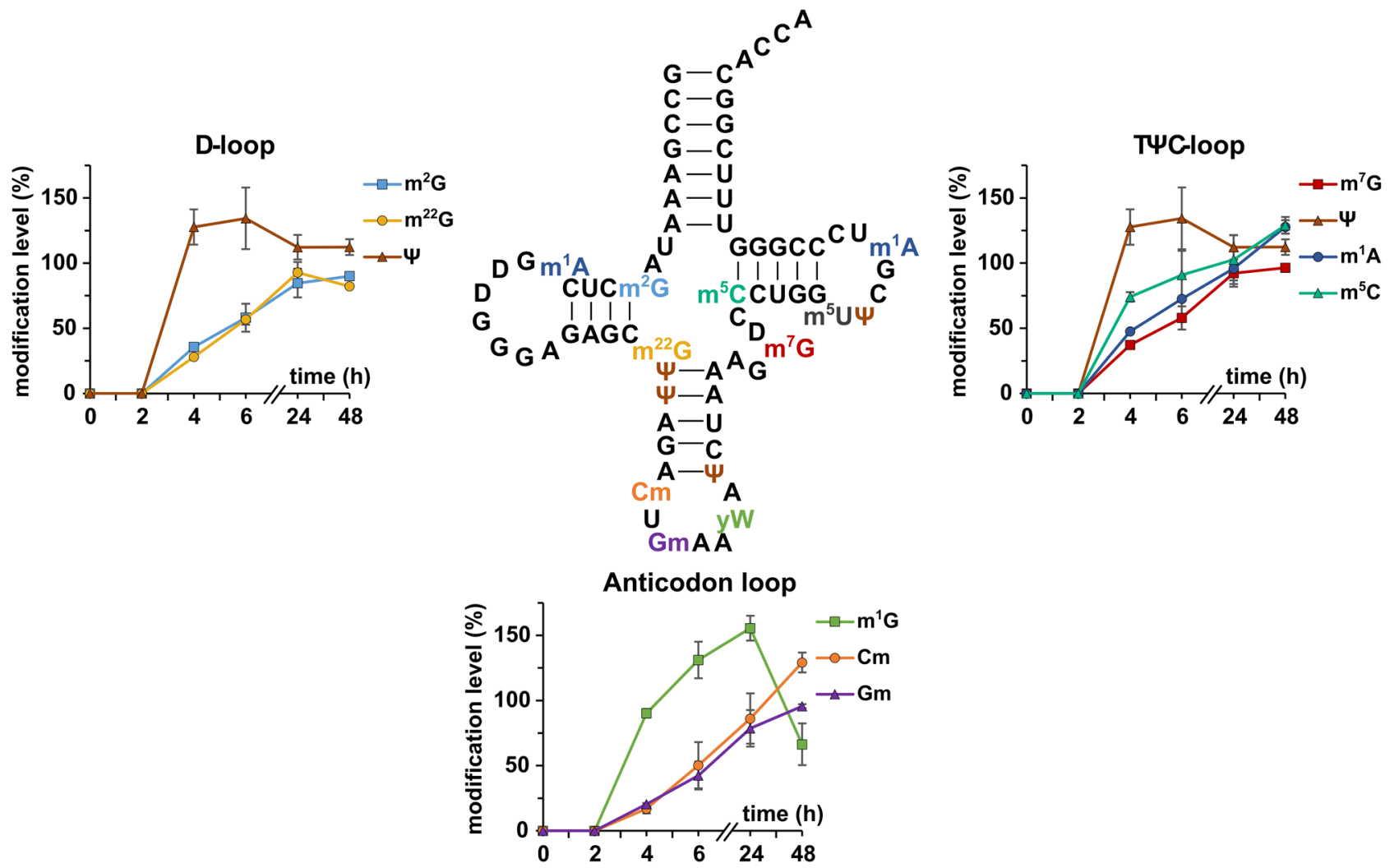

Fig. 4 Temporal placement of modified nucleosides in tRNA ${ }^{\text {Phe }}$ GAA. Cells were grown in unlabeled DMEM D0422 (supplemented with unlabeled uridine and adenine) for 7 days. At $T=0$ the medium was exchanged to DMEM D0422 supplemented with labeled uridine and adenine. Cells were harvested after set time points. tRNA ${ }^{\text {Phe }}$ was purified and analyzed by LC-MS/MS. Modifications are plotted next to their location in the D-, TYC- or anticodon loop. Plotted on the $y$-axis is the abundance of modification in new transcripts normalized to the respective nucleoside originating from unlabeled medium before experiment initiation $(T=0)$. The experiment was done in $n=3$ biol. replicates for time points 2,4 , and $48 \mathrm{~h}$ and in $n=6$ biol. replicates for time points 0 , 6 , and $24 \mathrm{~h}$. Symbols reflect the mean and error bars reflect standard deviation.

While the modified nucleosides of total tRNA are placed by various enzymes at various positions, we were interested to observe the modification process of defined enzymes in a defined substrate. For this purpose, we performed a pulse chase experiment and purified tRNA ${ }^{\text {Phe }}{ }_{\text {GAA }}$ after $0,2,4,6,24$, and $48 \mathrm{~h}$. The abundance of modified nucleosides in new tRNA transcripts is shown in Fig. 4. We observe an immediate high abundance of $\Psi$, which argues towards an immediate isomerization of e.g., U55 to $\Psi 55$ as observed in yeast ${ }^{22}$. In fact, we observe 1.5 -fold more $\Psi$ in the early lifetime of tRNA ${ }^{\mathrm{Phe}}{ }_{\mathrm{GAA}}$ as is expected from mature tRNA ${ }^{\text {Phe }}{ }_{\text {GAA }}$ (Fig. 1). At these early time points, the abundance of new tRNA ${ }^{\text {Phe }}{ }_{\text {GAA }}$ transcripts is low and thus the MS signal intensity is close to the lower limit of quantification (LLOQ). Uridine and its modifications have a low ionization efficiency and thus a higher LLOQ compared to other modified nucleosides. Thus, biological interpretation of $\Psi$ and $\mathrm{m}^{5} \mathrm{U}$ (Fig. S17) quantities must be conducted carefully. $\mathrm{D}$ is not included in this analysis, due to its artificial addition to the samples through the deaminase inhibitor tetrahydrouridine (which was omitted for analysis in Fig. 1 and thus allowed quantification of $D$ ). While $m^{7} G$ is the next modified nucleoside placed in yeast $\mathrm{tRNA}^{\text {Phe, }}$ our data hints towards a fast incorporation of $\mathrm{m}^{5} \mathrm{C}$ followed by $\mathrm{m}^{1} \mathrm{~A}$ and finally $\mathrm{m}^{7} \mathrm{G}$. Here, the dynamic placement of modifications in the TYC-loop seems to be slightly different between yeast and human. The slow incorporation of $\mathrm{m}^{2} \mathrm{G}$ in the $\mathrm{D}$-stem is in accordance with the reports from yeast. In the anticodon-loop (ac-loop), we observe a rather slow formation of $\mathrm{Gm}$ and $\mathrm{Cm}$. These modified nucleosides are not involved in structure stabilization but codon- anticodon binding ${ }^{41,42}$ and protein translation. Our data implies that structure stabilization by modified nucleosides is a key necessity and must thus happen early on, while ac-loop modifications are not immediately needed and are potentially placed on-demand. One exception is the formation of wybutosine $(\mathrm{yW})$. Its precursor modification $\mathrm{m}^{1} \mathrm{G}$ is immediately incorporated into tRNA ${ }^{\text {Phe }}$ before its abundance drops at later time points, presumably due to its further processing into $\mathrm{yW}$.

Dynamics of tRNA and 18S rRNA modifications. With the design of our pulse chase NAIL-MS assay, we can observe RNA maturation processes by quantifying the abundance of modified nucleosides in new transcripts. In addition, we can follow the fate of original RNA (unlabeled nucleosides in forward experiment) and observe methylation or demethylation events.

In Fig. 5a, we plotted the abundance of exemplary modified nucleosides from original total tRNA, which were present before medium exchange. Other modified nucleosides are shown in Fig. S18. Similar to our initial observations in S. cerevisiae ${ }^{31}$, we observed a constant loss of modified nucleosides from original tRNAs. In the common, unlabeled analysis of modified nucleosides, the decrease in modification density from original tRNA is not visible as it is masked by the addition of new methyl marks to original tRNAs at early time points (post-methylation) and by quickly modified new transcripts at later time points (ratio original/new transcripts in Figs. S18/19). Here, the postmethylation reaction is captured by the $\mathrm{CD}_{3}$-methionine added in the chase phase (medium-II) and is termed "methyl" in Fig. 5a. 
a

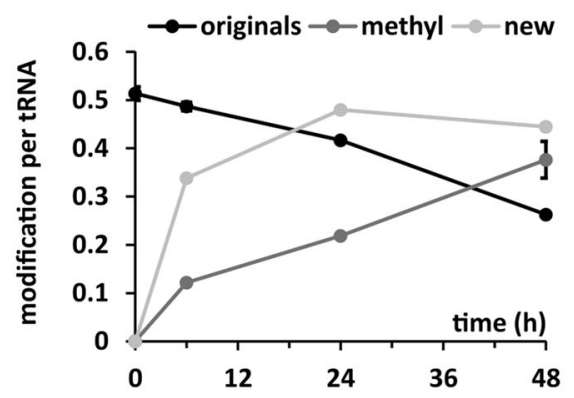

$\mathbf{m}^{1} \mathbf{A}$

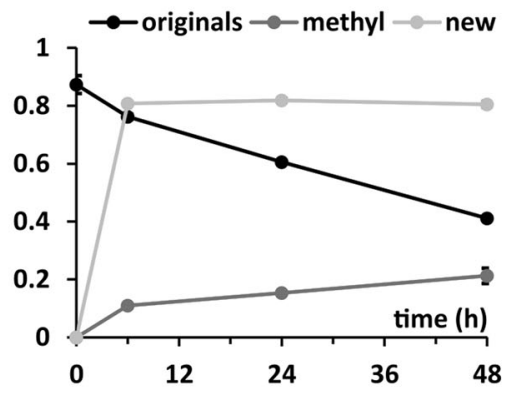

b

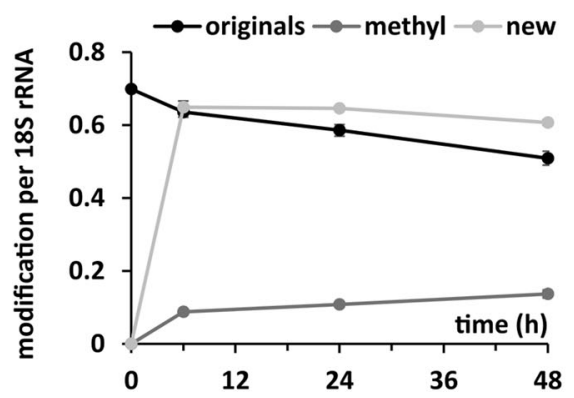

$m^{6} A$
$\mathrm{Cm}$

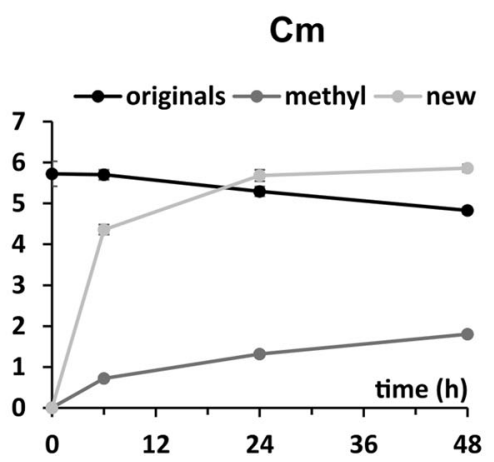

$\mathrm{Cm}$

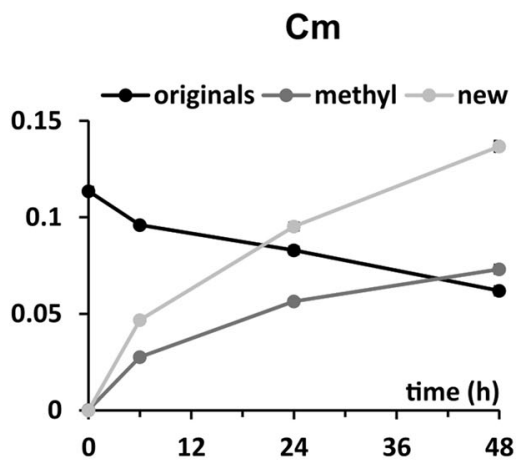

$\Psi$

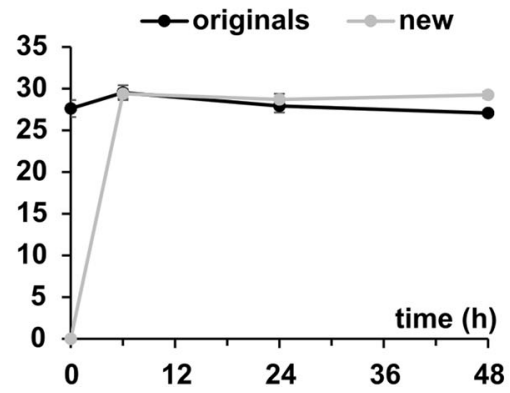

Fig. 5 Dynamics of modified nucleosides in total tRNA and 18S rRNA. a Results for total tRNA. b Results for 18S rRNA. Original nucleosides (originals, black line) existed before experiment initiation. Post-methylated nucleosides (methyl, dark grey line) are modifications arising from the methylation of original RNA after experiment initiation. New nucleosides (new, light grey line) show the incorporation of modification into new transcripts. Data points reflect the mean and standard deviations of $n=3$ biol. replicates.

Intriguingly, the extent of post-methylation depends on the modified nucleoside. For $\mathrm{m}^{7} \mathrm{G}$ and $\mathrm{Cm}$, it is more pronounced compared to $\mathrm{m}^{1} \mathrm{~A}$. Interestingly, many modified nucleosides which are placed almost immediately after transcription, show low amounts of post-methylation while those with a delayed incorporation showed substantial post-methylation.

Similar to tRNA, ribosomal RNA nucleosides are modified, mainly at locations close to the functional region of the ribosome ${ }^{25}$. From yeast studies, it is known that most ribose rRNA modifications are inserted immediately or even cotranscriptionally ${ }^{43}$. For $\Psi$ and other base modifications, the time point of placement during rRNA maturation is yet unknown. In a forward pulse-chase experiment, we have isolated 18S rRNA and quantified the abundance of the original and new modified nucleosides. As expected from yeast, ribose methylations appear early on in new $18 \mathrm{~S}$ rRNA transcripts. Intriguingly, $\mathrm{m}^{6} \mathrm{~A}$ and $\Psi$ are inserted as fast or even faster. This indicates an immediate placement after transcription which is in agreement with their inaccessibility at later stages of ribosome biogenesis (Fig. S19).

Impact of methylation stress on tRNA modification processes. We have recently applied NAIL-MS to profile bacterial tRNA damage by methylating agents ${ }^{29}$ and described the repair mechanisms in vivo ${ }^{37}$. With the goal to study the stress response in human cells, we determined the effect of methyl methanesulfonate (MMS) on growth of HEK 293 cells (Fig. S20). In these experiments, we observed a strong influence of trypsinization on cell survival, which we avoided in later experiments.

Until now, it was not possible to study the extent of $\mathrm{m}^{1} \mathrm{~A}$ and $\mathrm{m}^{7} \mathrm{G}$ damage formation in human RNA due to the presence of enzymatically placed $\mathrm{m}^{1} \mathrm{~A}$ and $\mathrm{m}^{7} \mathrm{G}$. With our cell culture labeling scheme, we succeeded to implement a methylome discrimination assay and determine the absolute abundance of these major RNA damages. For this purpose, cells were grown in $\mathrm{CD}_{3}$-methionine supplemented medium for 7 days before addition of $1 \mathrm{mM}$ MMS. While enzymatically placed methylations are $\mathrm{CD}_{3}$-labeled, MMS damaged sites are $\mathrm{CH}_{3}$-labeled and thus easily distinguishable from the enzymatic sites by mass spectrometry. To enable the tracing of the damaged tRNAs without interference of new transcripts, we included a switch to fully labeled media $\left({ }^{13} \mathrm{C} /{ }^{15} \mathrm{~N}\right.$-nucleoside body $\left.+\mathrm{CD}_{3}\right)$ for labeling of new transcripts. The timeline and concept is given in Fig. 6a. Samples of MMS and MOCK treated cells were taken before and after $1 \mathrm{~h}$ of MMS exposure and up to $6 \mathrm{~h}$ after removal of MMS, where cells were left to recover from MMS treatment.

From these samples, we purified tRNA ${ }_{\text {Phe }}{ }_{\text {GA }}$ and quantified the abundance of canonical and modified nucleosides. By comparison of canonical nucleosides, we could observe a higher ratio of new transcripts over original transcripts in the unstressed samples compared to the stressed samples (Fig. S21). This is to be expected as stressed cells stop growing and thus less transcription and translation are taking place. In addition, the prolonged abundance of original tRNA suggests that methylation stress does not lead to extensive degradation of tRNAs.

The quantification of methylated nucleosides derived from direct MMS methylation indeed showed formation of the known damage products $\mathrm{m}^{7} \mathrm{G}$ and potentially $\mathrm{m}^{1} \mathrm{~A}$. In comparison to the natural abundance of these modified nucleosides $\left(\sim 0.5 \mathrm{~m}^{7} \mathrm{G}\right.$ and $1 \mathrm{~m}^{1} \mathrm{~A}$ per tRNA $\left.{ }^{\mathrm{Phe}}{ }_{\mathrm{GAA}}\right)$, the damage accounts for less than $1 \%$ of these methylated nucleosides (Fig. 6b). In other words, only 1 out of around 200 tRNA molecules gets an additional $\mathrm{m}^{7} \mathrm{G}$ by MMS damage. For $\mathrm{m}^{1} \mathrm{~A}$ the damage is found in 1 out of 1000 tRNAs $(0.1 \%)$. No other reported MMS damage products were detected in human tRNA ${ }^{\text {Phe }}$.

While RNA methylation damage repair was observed in E. coli, using a similar NAIL-MS approach, no demethylation was 

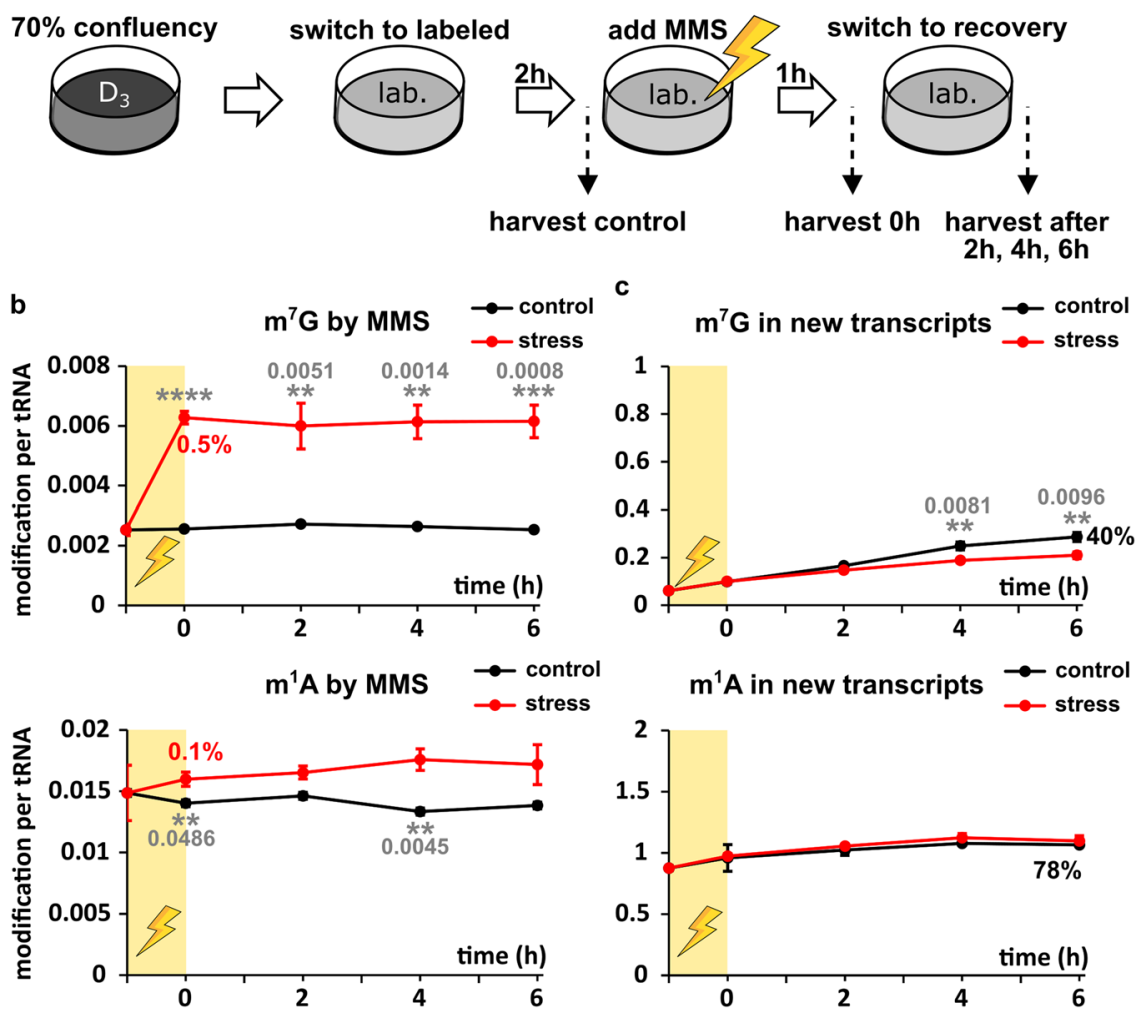

Fig. 6 Effect of methylation stress on tRNA modifications. a $70 \%$ confluent $\mathrm{CD}_{3}$-methionine labeled cells were incubated with fully labeled media for $2 \mathrm{~h}$ before the $\mathrm{LD}_{50}$ dose of methyl methanesulfonate (MMS, yellow shaded area) was added. Control samples were treated the same, substituting the MMS stock solution with PBS. After $1 \mathrm{~h}$ the stress (or control) media was replaced by fresh labeled media. After set time points, cells were harvested and tRNA $^{\text {Phe }}{ }_{\text {GAA }}$ was purified and subjected to LC-MS/MS analysis. $\mathbf{b}$ Unlabeled modifications were referenced to unlabeled canonicals to calculate the amount of modifications arising from direct methylation damage by MMS. Red numbers at time point 0 give the percentage of damaged nucleoside referenced to the naturally occurring amount of the respective modification (amount of original modification before experiment initiation). $\mathbf{c}$ Labeled modifications were referenced to labeled canonicals to calculate the amount of modification in new tRNA transcripts. The numbers at time point 6 give the percentage of modification amount in the control sample referenced to the naturally occurring amount of the respective modification. All experiments are from $n=3$ biol. replicates. Symbols reflect the mean and error bars reflect standard deviation. $P$-values from student t-test (equal distribution, two-sided): ${ }^{\star} p<0.05,{ }^{\star \star} p<$ $0.01,{ }^{\star * *} p<0.001$, and ${ }^{\star \star * *} p<0.0001$. Where reasonable, exact $P$-values are given as grey numbers in the figure.

detectable in the human cell line. Even $6 \mathrm{~h}$ after removal of the methylating agent, the abundance of non-enzymatically methylated $\mathrm{m}^{7} \mathrm{G}$ and $\mathrm{m}^{1} \mathrm{~A}$ stayed unchanged in the original transcripts. This observation indicates that human cells either have a highly expressed and fast acting RNA demethylase for RNA damage repair or no RNA demethylase at all. Also, the abundance of damaged nucleosides could be below a threshold limit to trigger damage repair in human cells.

We next asked the question, whether human cells react to methylation stress by adaptation of tRNA modifications. This adaptation can be mechanistically achieved by addition or removal of modified nucleosides to original tRNAs, by delayed modification of new tRNAs or a combination of both. For methylation stress, we did not see a difference in modified nucleoside abundance in original tRNA compared to the unstressed control (Fig. S22). (Note: In this NAIL-MS study, the supplemented methionine was $\mathrm{CD}_{3}$-labeled in both the pulse and the chase phase. Thus, it is not possible to observe the decrease of enzymatically placed modifications in original tRNA over time as shown in Fig. 5).

Finally, we studied the abundance of modified nucleosides in new tRNA transcripts in dependence of stress. For methylated guanosine derivatives $\left(\mathrm{m}^{7} \mathrm{G}, \mathrm{m}^{1} \mathrm{G}, \mathrm{m}^{2} \mathrm{G}\right.$, and $\left.\mathrm{m}^{22} \mathrm{G}\right)$, we observed a slightly reduced, but statistically significant (e.g., $\mathrm{m}^{7} \mathrm{G} \mathrm{p}_{6 \mathrm{~h}}=$ 0.0096 ) incorporation into tRNA ${ }_{\text {GA }}{ }_{\text {GA }}$ under stress compared to the control samples (Figs. $6 \mathrm{c}$ and S22). For $\mathrm{Cm}$ and $\mathrm{Gm}$, we observed a higher abundance under stressed conditions while $\mathrm{m}^{1} \mathrm{~A}$ or $\mathrm{m}^{5} \mathrm{C}$ were comparable. Our results imply that human cells (i) adapt their tRNA modifications to methylation stress by differentially modifying new transcripts and (ii) consider tRNA modification as a highly important process and thus continue even during stress exposure.

\section{Discussion}

Current analyses of the epitranscriptome are limited to snapshot moments and cannot truly follow dynamic processes inside cells. While NAIL-MS allows the observation of RNA modification adaptation processes 37,44 it was not possible to apply the technique in human cell culture due to the complexity of culture medium. ${ }^{13} \mathrm{C}_{6}$-glucose is a reasonable and economic option for stable isotope labeling ( $28 €$ per $50 \mathrm{~mL}$ medium $)^{45}$ but it suffers from the formation of multiple isotopologues which complicates its application especially when additional feeding with $\mathrm{CD}_{3}$ methionine is required. In such studies, the signals of partially ${ }^{13}$ C-labeled nucleosides and $\mathrm{CD}_{3}$-methylated nucleosides can overlap and quantification becomes impossible. In contrast, supplementation of various media with ${ }^{15} \mathrm{~N}_{5}$-adenine and ${ }^{13} \mathrm{C}_{5},{ }^{15} \mathrm{~N}_{2}$-uridine results in monoisotopic labeling with no overlap with naturally occurring ${ }^{13} \mathrm{C}$-isotopologues or artificially $\mathrm{CD}_{3}$-methylated nucleosides (305€ per $50 \mathrm{~mL}$ medium). Thus, a 
broad applicability and even quantification by isotope dilution mass spectrometry is possible. While we observe best results with dialyzed FBS, it is also possible to use regular FBS instead if it is preferable to the cells. If the nucleoside of interest is a $\mathrm{G}$ or A derivative, ${ }^{13} \mathrm{C}_{6}$-glucose labeling can be combined with supplementation of unlabeled adenine. This approach is less costly and produces monoisotopically labeled A and G derivatives with a ${ }^{13} \mathrm{C}_{5}$-ribose moiety (Figs. S5 and S6).

An important consideration for any NAIL-MS study is the constant supplementation with adenine and uridine, even when unlabeled medium is used to prevent activation of de novo synthesis pathways. Independently of the chosen nucleic acid labeling scheme, we strongly recommend validation experiments as shown in Fig. 3c. Such an experiment is crucial to later judge the statistical significance of e.g., pulse chase studies. For example, our validation experiment indicates that a less than 1.6 fold change in Um would not be biologically significant (Fig. S16). In such a case we recommend the direct comparison to a control sample (such as those in Fig. 6) to judge the accuracy of the received NAIL-MS data.

Furthermore, we suggest careful interpretation of new transcript data at early time points of pulse chase experiments. As described for $\Psi$ and $\mathrm{m}^{5} \mathrm{U}$ (Fig. S17), it is possible that some modified nucleosides are early on too close to the lower limit of quantification (LLOQ) in new transcripts and thus the received quantities must be interpreted carefully.

We have studied the temporal placement of modified nucleosides in tRNA $^{\text {Phe }}$ as a model. Our data implies that structure stabilization by modified nucleosides is a key necessity and must thus happen early on, while anticodon-loop modifications are not immediately needed and are potentially placed on-demand. One exception is the formation of wybutosine $(\mathrm{yW})$. Its precursor modification $\mathrm{m}^{1} \mathrm{G}$ is immediately incorporated into tRNA ${ }^{\text {Phe }}$ before its abundance drops at later time points, presumably due to its further processing into $\mathrm{yW}$. By NMR spectroscopy in combination with stable isotope labeling, Barraud et al. recently observed an inhibition of $\mathrm{m}^{22} \mathrm{G}$ formation by $\mathrm{m}^{2} \mathrm{G}^{22}$. In our hands, $\mathrm{m}^{22} \mathrm{G}$ is placed into tRNA ${ }^{\text {Phe }}$ as fast as is $\mathrm{m}^{2} \mathrm{G}$, but as both modifications are incorporated slowly it is possible that $\mathrm{m}^{22} \mathrm{G}$ is placed in a non$\mathrm{m}^{2} \mathrm{G}$ modified sub-population. This question might be approached by combining NAIL with oligonucleotide MS.

With NAIL-MS we are not limited to RNA modification studies in new transcripts. In addition, we can follow the fate of RNA modifications in mature transcripts. In human cells, we observe a constant loss of modified nucleosides from tRNAs, similar to our initial report in $S$. cerevisiae ${ }^{31}$. The extent of the decrease is similar for all modified nucleosides in tRNA $(\sim 50 \%$ lower within $48 \mathrm{~h}$ ) including non-methylated modifications, which argues towards a preferential degradation of modified tRNA. In 18S rRNA, we see a similar loss of modified nucleosides from original transcripts which is with $\sim 20 \%$ within $48 \mathrm{~h}$ less pronounced as in tRNA. The $\sim 2$-fold longer half-life of rRNA compared to tRNA ${ }^{46}$ supports our hypothesis of preferred degradation of modified RNA which is most likely connected to the life time of RNA.

The constant loss of pre-existing modifications from original RNA is masked in the early time points of the experiment by observable post-transcriptional methylation of original RNA. For many modified nucleosides, the extent of post-methylation of existing transcripts is connected to the extent of modification in new transcripts (Figs. S18 and S19). Some modified nucleosides such as $\mathrm{m}^{7} \mathrm{G}, \mathrm{m}^{3} \mathrm{U}, \mathrm{m}^{3} \mathrm{C}, \mathrm{mcm}^{5} \mathrm{~s}^{2} \mathrm{U}$ and $\mathrm{Um}$ show no correlation between post-methylation and new methylation abundance. Except $\mathrm{m}^{7} \mathrm{G}$, all these modified nucleosides are placed in or close to the anticodon-loop which indicates that the modification extent at these positions reflects rather demand than maturation. Another hypothesis for the post-methylation arises from reports on tRNA demethylation. For $\mathrm{m}^{1} \mathrm{~A}$ and $\mathrm{m}^{3} \mathrm{C}$, demethylation by members of the ALKBH family has been proposed ${ }^{9,47,48}$. Such a demethylated site might be target to re-methylation and this process would lead to the formation of post-methylated nucleosides. While the common analysis of tRNA modifications by sequencing and quantitative mass spectrometry provides a static view on the substrates of ALKBH enzymes, future NAIL-MS experiments will shed light onto the dynamic performance of these enzymes in vivo.

Such a detailed analysis is especially important for understanding the processes behind stress induced adaptation of tRNA modifications. To this end, we have studied the impact of methylation stress on tRNA modifications. Even at a harsh dose of MMS (1 mM), we observe only 1 damage derived $\mathrm{m}^{1} \mathrm{~A}$ and $5 \mathrm{~m}^{7} \mathrm{G}$ per 1000 tRNAs. Other damage products were not observed. Intriguingly, these damages do not seem to be repaired in human cells.

In our hands, methylation stress has no impact on the abundance of modified nucleosides in tRNA present during the stress exposure. In contrast, the abundance of some modified nucleosides is slightly, but significantly changed in new transcripts. This indicates that cells regulate their tRNA modifications on the level of new transcripts and not existing transcripts. Overall modification processes of tRNA are not stalled during stress recovery which indicates that properly modified tRNAs are of high importance to the cell.

NAIL-MS is a powerful technique which depends, as common to state-of-the-art mass spectrometry of modified nucleosides, on a complete enzymatic digest to the nucleoside building block. Thus, all sequence context surrounding modified nucleosides is lost and the technique relies strongly on the purity of the sample. This is especially important for $\mathrm{mRNA}^{49}$. If reliable mRNA purification is possible, the true dynamics of $\mathrm{m}^{6} \mathrm{~A}$ and other mRNA modifications becomes finally available through NAIL-MS.

\section{Methods}

Salts, reagents, media, and nucleosides. All salts, reagents and media were obtained from Sigma-Aldrich (Munich, Germany) at molecular biology grade unless stated otherwise. The isotopically labeled compounds ${ }^{13} \mathrm{C}_{5},{ }^{15} \mathrm{~N}_{2}$-Uridine (Ribose- ${ }^{13} \mathrm{C}_{5}$, $\left.98 \% ;{ }^{15} \mathrm{~N}_{2}, 96-98 \%\right)$ and ${ }^{15} \mathrm{~N}_{5}$-Adenine $\left({ }^{15} \mathrm{~N}_{5}, 98 \%\right)$ were obtained from Cambridge Isotope Laboratories (Tewksbury, MA, USA). Unlabeled glutamine, isotopically labeled L-glutamine-amide- ${ }^{15} \mathrm{~N}\left(98\right.$ atom $\left.\%{ }^{15} \mathrm{~N}\right)$, L-aspartic- ${ }^{15} \mathrm{~N}$ acid $\left(98\right.$ atom $\left.\%{ }^{15} \mathrm{~N}\right)$ and $\left(\mathrm{D}_{3}\right)$-L-methionine (98 atom\% D) were obtained from Sigma-Aldrich. Isotopically labeled ${ }^{13} \mathrm{C}_{6}$-glucose ( $\geq 99$ atom $\%{ }^{13} \mathrm{C}$ ) was obtained from Eurisotope (Saarbruecken, Germany). All solutions and buffers were made with water from a Sartorious arium ${ }^{\circledR}$ pro ultrapure water system (Goettingen, Germany). The nucleosides adenosine (A), cytidine $(C)$, guanosine $(G)$ and uridine $(U)$, were obtained from Sigma-Aldrich. 1Methyladenosine $\left(\mathrm{m}^{1} \mathrm{~A}\right)$, N3-methylcytidine $\left(\mathrm{m}^{3} \mathrm{C}\right)$, N6-methyladenosine $\left(\mathrm{m}^{6} \mathrm{~A}\right)$, 7 methylguanosine $\left(\mathrm{m}^{7} \mathrm{G}\right)$, 5-methylcytidine $\left(\mathrm{m}^{5} \mathrm{C}\right)$, 5-methyluridine $\left(\mathrm{m}^{5} \mathrm{U}\right), 2^{\prime}-\mathrm{O}$ methylcytidine $(\mathrm{Cm}), 2^{\prime}$-O-methylguanosine $(\mathrm{Gm}), 1$-methylguanosine $\left(\mathrm{m}^{1} \mathrm{G}\right), \mathrm{N} 2$ methylguanosine $\left(\mathrm{m}^{2} \mathrm{G}\right)$, 2-dimethylguanosine $\left(\mathrm{m}^{22} \mathrm{G}\right)$, pseudouridine $(\Psi)$, inosine $(\mathrm{I})$, 2'-O-methyluridine (Um), 2'-O-methyladenosine (Am), and 5-

methoxycarbonylmethyl-2-thiouridine $\left(\mathrm{mcm}^{5} \mathrm{~s}^{2} \mathrm{U}\right)$ were obtained from Carbosynth (Newbury, UK). Dihydrouridine (D) was obtained from Apollo Scientific (Stockport, UK). N6-threonylcarbamoyladenosine $\left(\mathrm{t}^{6} \mathrm{~A}\right)$ was obtained from TRC (North York, Canada). N3-methyluridine $\left(\mathrm{m}^{3} \mathrm{U}\right)$ and $\mathrm{N} 6$-isopentenyladenosine $\left(\mathrm{i}^{6} \mathrm{~A}\right)$ were generous gifts from the Dedon lab. 5-carbamoylmethyl-2-thiouridine $\left(\mathrm{ncm}^{5} \mathrm{~s}^{2} \mathrm{U}\right)$ was a generous gift from the Helm lab. 1-Methylinosine $\left(\mathrm{m}^{1} \mathrm{I}\right)$ was a generous gift from STORM Therapeutics LTD (Cambridge, UK).

Cell culture. All cell culture media and supplements were obtained from SigmaAldrich (Munich, Germany) unless stated otherwise. Standard Basal medium for HEK 293 culture was DMEM D6546 high glucose supplemented with 10\% FBS and $0.584 \mathrm{~g} / \mathrm{L}$ L-glutamine. Cells were split 1:7 using standard procedures every 2-3 days to counter overgrowth. Cells cultured in DMEM medium were kept at $10 \% \mathrm{CO}_{2}$ for proper $\mathrm{pH}$ adjustment. For all experiments where labeling of nucleosides was involved DMEM D0422 without methionine and cystine was used. DMEM D0422 was supplemented with 10\% dialyzed FBS (Biowest, Nuaillé, France), $0.584 \mathrm{~g} / \mathrm{L}$ L-glutamine, $0.063 \mathrm{~g} / \mathrm{L}$ cystine (stock concentration $78.75 \mathrm{~g} / \mathrm{L}$ dissolved in $1 \mathrm{M} \mathrm{HCl}), 0.03 \mathrm{~g} / \mathrm{L}$ methionine, $0.05 \mathrm{~g} / \mathrm{L}$ uridine, and $0.015 \mathrm{~g} / \mathrm{L}$ adenine. Uridine, adenine and methionine were either added as unlabeled or labeled compounds depending on the desired labeling. HeLa cells were cultured and labeled using the same media. 
For Labeling in RPMI R0883, dialyzed FBS, glutamine, methionine, uridine, and adenine were added in the same concentrations as for DMEM D0422.

HAP1 cells were either labeled using DMEM D0422 as described above or IMDM I3390 where FBS, glutamine, uridine, adenine and methionine were added in the same concentrations as used for DMEM D0422 medium. Cells grown in RPMI or IMDM medium were kept at $5 \% \mathrm{CO}_{2}$ for proper $\mathrm{pH}$ adjustment.

Mouse embryonic stem cells (mESC) were cultured as recently reported ${ }^{50}$. Isotopically labeled compounds were added as described for regular cell culture labeling.

For biological replicates one culture was split into several flask at least $24 \mathrm{~h}$ prior to experiment initiation.

Cell lysis and RNA purification. Cells were directly harvested on cell culture dishes using $1 \mathrm{~mL}$ TRI reagent for T25 flasks or $0.5 \mathrm{~mL}$ TRI reagent for smaller dishes. The total RNA was isolated according to the supplier's manual with chloroform (Roth, Karlsruhe, Germany). tRNA and $18 \mathrm{~S}$ rRNA were purified by size exclusion chromatography (AdvanceBio SEC $300 \AA$, $2.7 \mu \mathrm{m}, 7.8 \times 300 \mathrm{~mm}$ for tRNA and BioSEC $1000 \AA \AA 2.7 \mu \mathrm{m}, 7.8 \times 300 \mathrm{~mm}$ for $18 \mathrm{~S}$ rRNA, Agilent Technologies) according to published procedures ${ }^{31,51}$. The RNA was resuspended in water $(35 \mu \mathrm{L})$.

Isoacceptor purification. The procedure was adapted from Hauenschild et al. ${ }^{13}$. For tRNA ${ }_{\text {GAA }}^{\text {Phe }}$ purification, a mixture of $1 \mu \mathrm{g}$ SEC-purified total tRNA and 100 pmol complementary oligonucleotide was heated to $90^{\circ} \mathrm{C}$ for $3 \mathrm{~min}$ in a total volume of $100 \mu \mathrm{L} 5 \times$ SSC buffer $(0.75 \mathrm{M} \mathrm{NaCl}, 75 \mathrm{mM}$ trisodiumcitrate $\mathrm{pH} 7)$ and subsequently incubated for $10 \mathrm{~min}$ at $65^{\circ} \mathrm{C}$. The sequence of the biotinylated $2^{\prime}$-deoxyoligonucleotide is $5^{\prime}$-(Biotin) AAATGGTGCCGAAACCCGGGATCGA ACCAGGGT-3' (Sigma Aldrich, Munich, Germany). For each sample, $25 \mu \mathrm{L}$ Magnetic Dynabeads ${ }^{\circledast}$ MyOne $^{\mathrm{mm}}$ Streptavidin T1 (Thermo Fisher Scientific, Darmstadt, Germany) were primed three times in Binding and Wash buffer $(5 \mathrm{mM}$ Tris- $\mathrm{HCl} \mathrm{pH} \mathrm{7.5,} 0.5 \mathrm{mM}$ EDTA, $1 \mathrm{M} \mathrm{NaCl}$ ) and once in $5 \times \mathrm{SSC}$ buffer. An aliquot of $25 \mu \mathrm{L}$ magnetic beads in $5 \times$ SSC buffer was added to the prepared mixture of tRNA and oligonucleotide and incubated for $30 \mathrm{~min}$ at room temperature. Beads were then washed once with $1 \times$ SSC buffer and three times with $0.1 \times$ SSC buffer before elution of purified tRNA ${ }^{\text {Phe }_{\text {GAA }}}$ in $20 \mu \mathrm{L}$ Milli-Q water at $75^{\circ} \mathrm{C}$ for $3 \mathrm{~min}$.

Northern blot analysis. Isolated RNA samples and control oligonucleotides (in vitro synthesized tRNA ${ }_{\mathrm{UGA}}^{\mathrm{Ser}}$, tRNA fragment $\mathrm{Glycin}_{\mathrm{GCC}}$ ) were separated by implementing a $12 \%$ TBE-urea PAGE in $1 \times$ TBE buffer (Roth, Karlsruhe, Germany). Samples were denatured at $90^{\circ} \mathrm{C}$ for $1 \mathrm{~min}$, directly loaded on the gel and run at $275 \mathrm{~V}$ for $40 \mathrm{~min}$. The RNA was then transferred onto a Hybond-N + nylonmembrane (GE Healthcare, Chicago, US) at $375 \mathrm{~mA}, 4^{\circ} \mathrm{C}$ in $1 \times \mathrm{TBE}$ buffer for $2 \mathrm{~h}$ and subsequently crosslinked twice with UV light at the energy of $120 \mathrm{~mJ} /$ $\mathrm{cm}^{2}$. The membrane was incubated in hybridization buffer (5x Denhardt's solution, $1 \%$ SDS, $6.6 \times$ SSPE) for $30 \mathrm{~min}$ before $100 \mathrm{pmol}$ of the respective probe was added. Fluorescent probes ( $3^{\prime}$ and $5^{\prime}$ Cyanine- 3 modified, from Sigma-Aldrich, Munich, Germany) were designed to overlap with $\sim 30 \mathrm{nt}$ of the target RNA using the same sequence for tRNA ${ }^{\text {Phe }}$ as used for isoacceptor purification. The sequence of all probes used can be found in Table S2. Hybridization was performed overnight at $37^{\circ} \mathrm{C}$ in a shaking incubator. After two wash steps in $2 \times$ SSPE, $0.5 \%$ SDS for 10 min at room temperature the membrane was imaged at an Amersham Imager 680. Stripping was done by pouring boiling $0.1 \times$ SSPE buffer onto the membrane and incubation for $5 \mathrm{~min}$. To get rid of remaining signal completely this procedure was repeated 10 times before reprobing.

Sequencing. Analysis of tRNA ${ }^{\mathrm{Phe}}{ }_{\mathrm{GAA}}$ purity by deep sequencing was performed by mild RNA fragmentation under strong alkaline conditions $\left(5 \mathrm{~min}, 96^{\circ} \mathrm{C}, \mathrm{pH} 9.2\right)$. Resulting fragments were $3^{\prime}$-dephosphorylated by Antarctic phosphatase (New England Biolabs, Frankfurt, Germany) and 5'-phosphorylated by PNK/ATP treatment ${ }^{52}$. Library preparation was done using NEBNext ${ }^{\circledast}$ Multiplex Small RNA Library Prep Set for Illumina (NEB) according to the manufacturer's instructions. Quality of the library preparation was assessed by HS DNA chip on Bioanalyzer 2100 (Agilent). Sequencing was done using HiSeq1000 in single-read SR50 mode. Resulting raw reads ( $10 \mathrm{mln} / \mathrm{sample}$ ) were trimmed by trimmomatic v. 032 to remove the adapted sequence and aligned using bowtie 2 to the reference containing human rRNA sequences and non-redundant subset of human tRNAs. Over $90 \%$ of the reads was mapped by this approach, demonstrating that contamination by other cellular RNAs remains minor.

tRNA digestion for mass spectrometry. Total tRNA (300 ng) in aqueous digestion mix $(30 \mu \mathrm{L})$ was digested to single nucleosides by using $2 \mathrm{U}$ alkaline phosphatase, $0.2 \mathrm{U}$ phosphodiesterase I (VWR, Radnor, Pennsylvania, USA), and $2 \mathrm{U}$ benzonase in Tris ( $\mathrm{pH} 8,5 \mathrm{mM}$ ) and $\mathrm{MgCl}_{2}(1 \mathrm{mM})$ containing buffer. Furthermore, $0.5 \mu \mathrm{g}$ tetrahydrouridine (Merck, Darmstadt, Germany), $1 \mu \mathrm{M}$ butylated hydroxytoluene, and $0.1 \mu \mathrm{g}$ pentostatin were added to avoid deamination and oxidation of the nucleosides. When quantification of dihydrouridine was intended tetrahydrouridine was omitted. After incubation for $2 \mathrm{~h}$ at $37^{\circ} \mathrm{C}, 20 \mu \mathrm{L}$ of LC-MS buffer A (QQQ) was added to the mixture and then filtered through 96-well filter plates (AcroPrep Advance $35010 \mathrm{~K}$ Omega, PALL Corporation, New York, USA) at
$3000 \times g$ and $4^{\circ} \mathrm{C}$ for $30 \mathrm{~min}$. A stable isotope labeled internal standard (SILIS) was produced in $\mathrm{S}$. cerevisiae using ${ }^{13} \mathrm{C}$ and ${ }^{15} \mathrm{~N}$ rich growth medium (Silantes, Munich, Germany, Product\# 111601402) following recently described procedures ${ }^{16,31} .1 / 10$ Vol. of SILIS was added to each filtrate before analysis by QQQ mass spectrometry. For each sample $10 \mu \mathrm{L}$ were injected ( $60 \mathrm{ng}$ of sample tRNA).

High resolution mass spectrometry. The ribonucleosides were separated using a Dionex Ultimate 3000 HPLC system with a Synergi, $2.5 \mu \mathrm{m}$ Fusion-RP, $100 \AA$, $100 \times 2 \mathrm{~mm}$ column (Phenomenex ${ }^{\oplus}$, Torrance, California, USA). Mobile phase A was $10 \mathrm{mM}$ ammonium formate and mobile phase B was $80 \%$ acetonitrile containing $2 \mathrm{mM}$ ammonium formate. Gradient elution started with $0 \% \mathrm{~B}$ and increased to $12 \% \mathrm{~B}$ after $10 \mathrm{~min}$ and to $80 \%$ after $12 \mathrm{~min}$. After 4 min elution at $80 \% \mathrm{~B}$ and subsequently regeneration of starting conditions to $100 \% \mathrm{~A}$ after $5 \mathrm{~min}$, the column was equilibrated at $100 \% \mathrm{~A}$ for $8 \mathrm{~min}$. The flow rate was $0.2 \mathrm{~mL} / \mathrm{min}$ and the column temperature $30^{\circ} \mathrm{C}$. High-resolution mass spectra were recorded by a ThermoFinnigan LTQ Orbitrap XL operated in positive ionization mode. The parameters of the mass spectrometer were tuned with a freshly mixed solution of uridine $(10 \mu \mathrm{M})$. Capillary voltage was set to $20 \mathrm{~V}$ and capillary temperature to $300^{\circ} \mathrm{C}$. Sheath gas and sweep gas flow rate was set to 0 , and auxiliary gas flow rate to 35 . Source voltage was set to $4.0 \mathrm{kV}$ and tube lens to $75 \mathrm{~V}$.

QQQ mass spectrometry. For quantitative mass spectrometry an Agilent 1290 Infinity II equipped with a diode-array detector (DAD) combined with an Agilent Technologies G6470A Triple Quad system and electrospray ionization (ESI-MS, Agilent Jetstream) was used. Operating parameters: positive-ion mode, skimmer voltage of $15 \mathrm{~V}$, cell accelerator voltage of $5 \mathrm{~V}, \mathrm{~N}_{2}$ gas temperature of $230^{\circ} \mathrm{C}$ and $\mathrm{N}_{2}$ gas flow of $6 \mathrm{~L} / \mathrm{min}$, sheath gas $\left(\mathrm{N}_{2}\right)$ temperature of $400^{\circ} \mathrm{C}$ with a flow of $12 \mathrm{~L} / \mathrm{min}$, capillary voltage of $2500 \mathrm{~V}$, nozzle voltage of $0 \mathrm{~V}$, and nebulizer at $40 \mathrm{psi}$. The instrument was operated in dynamic MRM mode (Table S3).

For separation a Synergi, $2.5 \mu \mathrm{m}$ Fusion-RP, $100 \AA, 100 \times 2 \mathrm{~mm}$ column (Phenomenex ${ }^{\oplus}$, Torrance, California, USA) at $35^{\circ} \mathrm{C}$ and a flow rate of $0.35 \mathrm{~mL} / \mathrm{min}$ was used in combination with a binary mobile phase of $5 \mathrm{mM} \mathrm{NH}_{4} \mathrm{OAc}$ aqueous buffer A, brought to $\mathrm{pH} 5.3$ with glacial acetic acid $(65 \mu \mathrm{L} / \mathrm{L})$, and an organic buffer B of pure acetonitrile (Roth, Ultra LC-MS grade, purity $\geq 99.98$ ). The gradient started at $100 \%$ solvent A for $1 \mathrm{~min}$, followed by an increase to $10 \%$ solvent B over 4 min. From 5 to $7 \mathrm{~min}$, solvent B was increased to $40 \%$ and maintained for $1 \mathrm{~min}$ before returning to $100 \%$ solvent $\mathrm{A}$ in $0.5 \mathrm{~min}$ and a $2.5 \mathrm{~min}$ re-equilibration period.

Calibration. For calibration, synthetic nucleosides were weighed and dissolved in water to a stock concentration of $1-10 \mathrm{mM}$. The calibration solutions ranged from 0.025 to $100 \mathrm{pmol}$ for each canonical nucleoside and from $0.00125 \mathrm{pmol}$ to $5 \mathrm{pmol}$ for each modified nucleoside. Each calibration was spiked with $10 \%$ SILIS. The sample data were analyzed by the quantitative and qualitative MassHunter Software from Agilent. The areas of the MRM signals were integrated for each modification. The values of integrated MS signals from target nucleosides were set into relation to the respective MS signals of the respective isotope labeled SILIS nucleosides after Eq. (1) to receive the nucleoside isotope factor (NIF):

$$
\mathrm{NIF}_{\text {nucleoside }}=\frac{\text { signal area }_{\text {nucleoside }}}{\text { signal area }}
$$

Results from Eq. (1) were plotted against the expected molar amount of nucleosides and regression curves were plotted through the data points. The slopes represent the respective relative response factors for the nucleosides (rRFN) and enable an absolute quantification. The principle is described in more detail in our published protocol ${ }^{16}$. The plotting of these calibration curves is done automatically by the quantitative MassHunter Software and should be checked manually for linearity.

Data analysis. Molar amounts of nucleosides in samples were calculated after Eq (2) using the signal areas of target compounds and SILIS in the samples and the respective rRFN, determined by calibration measurements. This step is done automatically by the quantitative MassHunter Software.

$$
n_{\text {sample nucleoside }}=\frac{\text { signal }_{\text {area }} \text { sample nucleoside }_{\text {rRFN }}}{\text { nucleoside } \bullet \text { signal area }_{\text {respective SIIIS }}}
$$

To make different samples quantitatively comparable, the molar amount of each modified nucleoside was normalized by the molar amount of injected RNA to receive the number of modifications per RNA. Therefore, the calculated amounts of injected canonicals were divided by their expected occurrence in the respective RNAs and averaged afterwards (see Eq. (3) for tRNA). The numbers for each canonical nucleoside were either taken from the sequence of $18 \mathrm{~S} r R N A, \mathrm{tRNA}^{\text {Phe }}$ (reported modifications subtracted $)^{32}$, or determined empirically for total tRNA analyses.

$$
n_{\mathrm{tRNA}}=\frac{\frac{n_{C}}{\# C}+\frac{n_{U}}{\# U}+\frac{n_{G}}{\# \mathrm{G}}+\frac{n_{A}}{\# A}}{4}
$$

In the case of NAIL-MS experiments, the different isotopologues were referenced to their respective labeled canonicals, so that original (unlabeled) modifications were referenced to original tRNA molecules and new (labeled) modifications were referenced to new tRNA molecules (see Eqs. (4) and (5)). 
Table S4 gives a summary of the calculations exemplarily for $\mathrm{m}^{7} \mathrm{G}$.

$$
\begin{aligned}
\# \bmod / \mathrm{tRNA}(\text { original }) & =\frac{n_{\text {sample nucleoside }}(\text { unlabeled })}{n_{\mathrm{tRNA}}(\text { unlabeled })} \\
\# \bmod / \mathrm{tRNA}(\mathrm{new}) & =\frac{n_{\text {sample nucleoside }}(\text { labeled })}{n_{\mathrm{tRNA}}(\text { labeled })}
\end{aligned}
$$

Statistics. All experiments were performed at least 3 times (biological replicates) to allow student $\mathrm{t}$-test analysis. $P$-values of student $\mathrm{t}$-test (unpaired, two-tailed, equal distribution) were calculated using Excel.

Reporting summary. Further information on research design is available in the Nature Research Reporting Summary linked to this article.

\section{Data availability}

Sequencing data are available under accession PRJEB41141 at ENA database. The data supporting the findings of this study are available from the corresponding authors upon reasonable request. Source data are provided with this paper.

Received: 22 April 2020; Accepted: 4 December 2020;

Published online: 15 January 2021

\section{References}

1. Mauer, J. et al. Reversible methylation of $\mathrm{m}(6) \mathrm{Am}$ in the $5^{\prime}$ cap controls mRNA stability. Nature 541, 371-375 (2017).

2. Zheng, G. et al. ALKBH5 is a mammalian RNA demethylase that impacts RNA metabolism and mouse fertility. Mol. Cell 49, 18-29 (2013).

3. Jia, G. et al. N6-methyladenosine in nuclear RNA is a major substrate of the obesity-associated FTO. Nat. Chem. Biol. 7, 885-887 (2011).

4. Tang, C. et al. ALKBH5-dependent m6A demethylation controls splicing and stability of long 3'-UTR mRNAs in male germ cells. Proc. Natl Acad. Sci. USA 115, E325-E333 (2018).

5. Wei, J. et al. Differential $\mathrm{m}(6) \mathrm{A}, \mathrm{m}(6) \mathrm{Am}$, and $\mathrm{m}(1) \mathrm{A}$ demethylation mediated by FTO in the cell nucleus and cytoplasm. Mol. Cell 71, 973-985 e975 (2018).

6. Mauer, J. \& Jaffrey, S. R. FTO, m(6) Am, and the hypothesis of reversible epitranscriptomic mRNA modifications. FEBS Lett. 592, 2012-2022 (2018).

7. Zhou, J. et al. N(6)-methyladenosine guides mRNA alternative translation during integrated stress response. Mol. Cell 69, 636-647 e637 (2018).

8. Zhang, X. et al. Structural insights into FTO's catalytic mechanism for the demethylation of multiple RNA substrates. Proc. Natl Acad. Sci. USA 116, 2919-2924 (2019).

9. Liu, F. et al. ALKBH1-mediated tRNA demethylation regulates translation. Cell 167, 816-828 e816 (2016).

10. Gattoni, R., Keohavong, P. \& Stevenin, J. Splicing of the E2A premessenger RNA of adenovirus serotype 2. Multiple pathways in spite of excision of the entire large intron. J. Mol. Biol. 187, 379-397 (1986).

11. Chan, C. T. et al. A quantitative systems approach reveals dynamic control of tRNA modifications during cellular stress. PLoS Genet. 6, el001247 (2010).

12. Carell, T. et al. Structure and function of noncanonical nucleobases. Angew. Chem. Int. Ed. Engl. 51, 7110-7131 (2012).

13. Hauenschild, R. et al. The reverse transcription signature of N-1methyladenosine in RNA-Seq is sequence dependent. Nucleic Acids Res. 43, 9950-9964 (2015).

14. Clark, W. C., Evans, M. E., Dominissini, D., Zheng, G. \& Pan, T. tRNA base methylation identification and quantification via high-throughput sequencing. RNA 22, 1771-1784 (2016).

15. Brandmayr, C. et al. Isotope-based analysis of modified tRNA nucleosides correlates modification density with translational efficiency. Angew. Chem. Int. Ed. Engl. 51, 11162-11165 (2012).

16. Borland K. et al. Production and application of stable isotope-labeled internal standards for RNA modification analysis. Genes 10, 26 (2019).

17. Pan, T. Modifications and functional genomics of human transfer RNA. Cell Res. 28, 395-404 (2018).

18. Dittmar, K. A., Sorensen, M. A., Elf, J., Ehrenberg, M. \& Pan, T. Selective charging of tRNA isoacceptors induced by amino-acid starvation. EMBO Rep. 6, 151-157 (2005).

19. Klug, A., Ladner, J. \& Robertus, J. D. The structural geometry of co-ordinated base changes in transfer RNA. J. Mol. Biol. 89, 511-516 (1974).

20. Kim, S. H. et al. Three-dimensional tertiary structure of yeast phenylalanine transfer RNA. Science 185, 435-440 (1974).

21. Shi, H. \& Moore, P. B. The crystal structure of yeast phenylalanine tRNA at 1.93 A resolution: a classic structure revisited. RNA 6, 1091-1105 (2000).
22. Barraud, P. et al. Time-resolved NMR monitoring of tRNA maturation. Nat. Commun. 10, 3373 (2019).

23. Chan, C., Pham, P., Dedon, P. C. \& Begley, T. J. Lifestyle modifications: coordinating the tRNA epitranscriptome with codon bias to adapt translation during stress responses. Genome Biol. 19, 228 (2018).

24. Deng, W. et al. Trm9-catalyzed tRNA modifications regulate global protein expression by codon-biased translation. PLoS Genet. 11, e1005706 (2015).

25. Sloan, K. E. et al. Tuning the ribosome: the influence of rRNA modification on eukaryotic ribosome biogenesis and function. RNA Biol. 14, 1138-1152 (2017)

26. Yoon, A. et al. Impaired control of IRES-mediated translation in X-linked dyskeratosis congenita. Science 312, 902-906 (2006).

27. Helm, M. \& Motorin, Y. Detecting RNA modifications in the epitranscriptome: predict and validate. Nat. Rev. Genet. 18, 275-291 (2017).

28. Motorin, Y. \& Helm, M. Methods for RNA modification mapping using deep sequencing: established and new emerging technologies. Genes 10, 35 (2019).

29. Reichle, V. F., Weber, V. \& Kellner, S. NAIL-MS in E. coli determines the source and fate of methylation in tRNA. Chembiochem 19, 2575-2583 (2018)

30. Reichle, V. F., Petrov, D. P., Weber, V., Jung, K. \& Kellner, S. NAIL-MS reveals the repair of 2-methylthiocytidine by AlkB in E. coli. Nat. Commun. 10, 5600 (2019).

31. Heiss, M., Reichle, V. F. \& Kellner, S. Observing the fate of tRNA and its modifications by nucleic acid isotope labeling mass spectrometry: NAIL-MS. RNA Biol. 14, 1260-1268 (2017).

32. Boccaletto, P. et al. MODOMICS: a database of RNA modification pathways. 2017 update. Nucleic Acids Res. 46, D303-D307 (2018).

33. Tuorto, F. et al. RNA cytosine methylation by Dnmt2 and NSun2 promotes tRNA stability and protein synthesis. Nat. Struct. Mol. Biol. 19, 900-905 (2012).

34. Blobstein, S. H., Grunberger, D., Weinstein, I. B. \& Nakanishi, K. Isolation and structure determination of the fluorescent base from bovine liver phenylalanine transfer ribonucleic acid. Biochemistry 12, 188-193 (1973).

35. Perche-Letuvee, P., Molle, T., Forouhar, F., Mulliez, E. \& Atta, M. Wybutosine biosynthesis: structural and mechanistic overview. RNA Biol. 11, 1508-1518 (2014).

36. Macon, J. B. \& Wolfenden, R. 1-Methyladenosine. Dimroth rearrangement and reversible reduction. Biochemistry 7, 3453-3458 (1968).

37. Reichle, V. F. et al. Surpassing limits of static RNA modification analysis with dynamic NAIL-MS. Methods 156, 91-101 (2019).

38. Jensen, K. F., Dandanell, G., Hove-Jensen, B. \& WillemoEs, M. Nucleotides, nucleosides, and nucleobases. EcoSal Plus 3, 3.6.2 (2008).

39. Motorin, Y. \& Helm, M. tRNA stabilization by modified nucleotides. Biochemistry 49, 4934-4944 (2010).

40. Kim, S. H. et al. The general structure of transfer RNA molecules. Proc. Natl Acad. Sci. USA 71, 4970-4974 (1974).

41. Ashraf, S. S. et al. Role of modified nucleosides of yeast tRNA(Phe) in ribosomal binding. Cell Biochem. Biophys. 33, 241-252 (2000).

42. Han, L., Guy, M. P., Kon, Y. \& Phizicky, E. M. Lack of 2'-O-methylation in the tRNA anticodon loop of two phylogenetically distant yeast species activates the general amino acid control pathway. PLoS Genet. 14, el007288 (2018).

43. Kos, M. \& Tollervey, D. Yeast pre-rRNA processing and modification occur cotranscriptionally. Mol. Cell 37, 809-820 (2010).

44. Heiss, M. \& Reichle, V. F. \& Kellner S. Observing the fate of tRNA and its modifications by nucleic acid isotope labeling mass spectrometry: NAIL-MS. RNA Biol. 14, 1-9 (2017).

45. Reichle, V. F. et al. Surpassing limits of static RNA modification analysis with dynamic NAIL-MS. Methods 156, 91-101 (2018).

46. Miller, B. G. The biological half-lives of ribosomal and transfer RNA in the mouse uterus. J. Endocrinol. 59, 81-85 (1973).

47. Chen, Z. et al. Transfer RNA demethylase ALKBH3 promotes cancer progression via induction of tRNA-derived small RNAs. Nucleic Acids Res. 47, 2533-2545 (2019).

48. Ueda, Y. et al. AlkB homolog 3-mediated tRNA demethylation promotes protein synthesis in cancer cells. Sci. Rep. 7, 42271 (2017).

49. Legrand, C. et al. Statistically robust methylation calling for wholetranscriptome bisulfite sequencing reveals distinct methylation patterns for mouse RNAs. Genome Res. 27, 1589-1596 (2017).

50. Rahimoff, R. et al. 5-Formyl- and 5-carboxydeoxycytidines do not cause accumulation of harmful repair intermediates in stem cells. J. Am. Chem. Soc. 139, 10359-10364 (2017)

51. Chionh, Y. H. et al. A multidimensional platform for the purification of noncoding RNA species. Nucleic Acids Res. 41, e168 (2013).

52. Galvanin, A. et al. Diversity and heterogeneity of extracellular RNA in human plasma. Biochimie 164, 22-36 (2019).

\section{Acknowledgements}

This study was funded through the Deutsche Forschungsgemeinschaft (KE1943/3-1). M.H., F.H., and S.K. thank Angie Kirchner, Thomas Carell and his group for instrument time (high-resolution mass spectrometer) and advice. 


\section{Author contributions}

M.H. and S.K. planned the experiments and wrote the manuscript. M.H., V.M., and F.H. conducted the experiments. M.H., Y.M., and S.K. performed data analysis.

\section{Funding}

Open Access funding enabled and organized by Projekt DEAL.

\section{Competing interests}

The authors declare no competing interests.

\section{Additional information}

Supplementary information is available for this paper at https://doi.org/10.1038/s41467020-20576-4

Correspondence and requests for materials should be addressed to S.K.

Peer review information Nature Communications thanks Guifang Jia and the other, anonymous, reviewer(s) for their contribution to the peer review of this work.
Reprints and permission information is available at http://www.nature.com/reprints

Publisher's note Springer Nature remains neutral with regard to jurisdictional claims in published maps and institutional affiliations.

(c) (i) Open Access This article is licensed under a Creative Commons Attribution 4.0 International License, which permits use, sharing, adaptation, distribution and reproduction in any medium or format, as long as you give appropriate credit to the original author(s) and the source, provide a link to the Creative Commons license, and indicate if changes were made. The images or other third party material in this article are included in the article's Creative Commons license, unless indicated otherwise in a credit line to the material. If material is not included in the article's Creative Commons license and your intended use is not permitted by statutory regulation or exceeds the permitted use, you will need to obtain permission directly from the copyright holder. To view a copy of this license, visit http://creativecommons.org/ licenses/by/4.0/.

(C) The Author(s) 2021 